\title{
Spontaneous apoptosis and $B C L 2$ gene expression as predictors of early death and short overall survival in acute leukemia patients: a prospective, case cohort study
}

\author{
Huda F. Ebiann ${ }^{1}$, Lobna A. El-korashi ${ }^{2}$, Ahmed Embaby $^{3}$, Marwa H. Hussien ${ }^{4}$ and Alshymaa A. Ahmed ${ }^{1 *}$ (i)
}

\begin{abstract}
Background: Spontaneous apoptosis and expression of $M C L 1, B C L 2$, and $B C L-X L$ may be useful prognostic markers in acute leukemia patients. The purpose of this study is to examine the prognosis in adult leukemia patients based on spontaneous apoptosis and anti-apoptosis gene expressions in circulating leukocytes.

Results: Early, late, and total apoptosis were significantly increased in peripheral blood leukocytes from patients diagnosed with acute myeloid leukemia (AML) and acute lymphoblastic leukemia (ALL) compared to controls and in cases of ALL versus AML $(P<0.001)$. Total apoptosis decreased significantly in AML and ALL patients who died early (ED); $P=0.001$ and $P=0.002$, respectively. Anti-apoptosis genes $M C L 1, B C L 2$, and $B C L-X L$ were upregulated in 62.4\%, $64.2 \%$, and $62.4 \%$ of the acute leukemia patients, respectively. Among the AML patients, the up-regulation of $B C L 2$ was paradoxically associated with increased apoptosis and low rates of ED. The expression levels of MCL1 and BCL-XL had no significant prognostic values; among patients diagnosed with non-acute promyelocytic leukemia (non-APL$A M L)$, total spontaneous apoptosis, expression of $B C L 2$, and performance status were independent predictors of overall survival (OS).

Conclusion: Total spontaneous apoptosis and BCL2 gene expression may be valuable independent markers for OS in patients with non-APL-AML. Moreover, in ALL patients decreased levels of spontaneous apoptosis were associated with $E D$, although this was not a significant predictor of OS.
\end{abstract}

Keywords: Acute leukemia, Spontaneous apoptosis, BCL2, MCL1, BCL-XL

\section{Background}

Apoptosis is the process of programed cell death that plays an important role in controlling cellular differentiation and proliferation. Among these roles, leukemic cells with alterations in one or both of the apoptotic pathways can acquire a survival advantage over their normal counterparts and can develop resistance to chemotherapeutic drugs. Despite the advancements in leukemia therapy,

\footnotetext{
*Correspondence: alshymaa2110@gmail.com

${ }^{1}$ Clinical Pathology Department, Faculty of Medicine, Zagazig University,

Zagazig City, Al Sharqia Governorate, Egypt

Full list of author information is available at the end of the article
}

the outcome remains problematic; therefore, markers that correlate with prognosis and the likelihood of relapse would be very helpful in the ongoing disease management [1].

Some recent studies have focused on the role of spontaneous and/or treatment-induced cellular apoptosis for risk stratification of acute leukemia patients. Chemotherapeutic agents mainly act by promoting the apoptosis of rapidly dividing cancer cells. Moreover, apoptosis may be evaluated as a direct measure of the intrinsic sensitivity of blast cells to chemotherapeutic treatment. Assays that detect cell surface Annexin V in combination with 
propidium iodide (PI) are typically sensitive, easy, and reproducible methods for quantitative evaluation of cellular apoptosis compared with other traditional methods. The flow cytometric evaluation of cell viability via the detection of Annexin V/PI has been effective and widely used [2].

The B-cell lymphoma 2 (BCL2) family of proteins is the key regulator of apoptosis. The expression of $B C L 2$ may be involved in cancer pathophysiology and the development of resistance to chemotherapy. Expression patterns that feature three of the most prominent antiapoptotic genes, including $B C L 2$, myeloid-cell leukemia 1 (MCL1), and B-cell lymphoma-extra-large (BCL-XL), may be useful in the development of tools for identifying prognosis in patients diagnosed with acute leukemia. Moreover, their protein products may act as targets for chemotherapy [3].

\section{Methods}

\section{Patients selection, diagnosis, and stratification}

This prospective study was conducted from January 2019 to January 2020 at the Clinical Hematology Unit of the departments of Internal Medicine and Clinical Pathology, Faculty of Medicine. Overall, 98 consecutive Egyptian adults of both genders who were newly diagnosed with acute leukemia and had not yet undergone therapeutic treatment were included in this study. Patients who had initiated chemotherapy or who refused to sign the informed consent form were excluded from this study. Due to the intermediate rate of acute leukemia, all patients admitted to the hospital during the study period who were eligible for inclusion were enrolled in this study.

The patients were diagnosed and classified using the French-American-British morphological system along with the World Health Organization immunological classifications [4]. Cytogenetic analysis was performed through standard karyotyping and fluorescence in situ hybridization. The patients were stratified based on their performance status according to Eastern Cooperative Oncology Group (ECOG) [5] and cytogenetic analysis as per the standard cytogenetic risk groups. A peripheral blood sample was withdrawn from the patients at the time of diagnosis to be processed within $24 \mathrm{~h}$.

\section{Evaluation of spontaneous apoptosis}

The samples were prepared for flow cytometry using BD FACS lysing solution, Annexin V binding buffer, Annexin V (Fluorescein isothiocyanate (FITC)), and PI (PE) (BD Biosciences, USA), in accordance with the manufacturer's instructions. Cell acquisition and analysis were performed using FACS Calibur flow cytometer and CellQuest software (BD Biosciences. San Jose, USA).
Instrument compensation and gating strategy were performed based on previous literatures [6, 7], respectively. Early apoptosis is defined as Annexin V-positive/PInegative cells and late apoptosis as Annexin V-positive/ PI-positive cells. The apoptotic indices are expressed as the percentage to the total number of cells in the gated region and total apoptosis was calculated by the summation of early and late apoptotic indices [8].

\section{Expression of anti-apoptotic genes}

The mononuclear cells were isolated from whole blood using standard Ficoll density gradient centrifugation methods. The total RNA was extracted from the mononuclear cells using the Trizol reagent and RNeasy mini kit (Qiagen, Germany). RNA concentration was determined using Qubit4 fluorometer and Qubit ${ }^{\mathrm{TM}}$ RNA HS Assay Kit (Thermo Fisher Scientific, Inc., USA), followed by the generation of complementary DNA using HisenScript ${ }^{\text {tm }}$ cDNA synthesis kit (iNtRON Biotechnology, South Korea). All the procedures performed were in accordance with the manufacturer's guidelines. Real-time PCR was performed using the Mx3005P system (Agilent Technologies, USA). The reaction mixture (20 ul) contained the following: $2 \mathrm{ul}$ of cDNA, $6 \mu \mathrm{L}$ of nuclease free water, $10 \mu \mathrm{L}$ of SybrGreen Master Mix (TOPreal ${ }^{\mathrm{TM}}$ qPCR 2X PreMIX, Enzynomics, Korea), and $2 \mu \mathrm{L}$ of gene-specific primers (final concentration $=50 \mathrm{nM}$ for each). Primers sequence and the annealing temperature of $B C L 2$ : forward $5^{\prime}$-TCG CCCTGTGGATGACTGA- $3^{\prime}$, reverse $5^{\prime}$-CAGAGACAG CCAGGAGAAATCA $-3{ }^{\prime}$, annealing temperature $56{ }^{\circ} \mathrm{C}$ [9], and those for MCL1: forward 5'-AGAAAGCTGCAT CGAACCAT- $3^{\prime}$, reverse 5'-CCAGCTCCTA CTCCAG CAAC- $3^{\prime}$ and $B C L-X L$ : forward 5'-CTGAATCGGAGA TGGAGACC $-3^{\prime}$, reverse $5^{\prime}$-TGGGATGTCAGGTCA CTGAA $-3^{\prime}$, annealing temperature $60{ }^{\circ} \mathrm{C}$ for both [10]. The reaction conditions were as follows: initial denaturation at $95{ }^{\circ} \mathrm{C}$ for $15 \mathrm{~min}$, followed by 35 cycles of denaturation at $95{ }^{\circ} \mathrm{C}$ for $30 \mathrm{~s}$, and annealing and extension for $60 \mathrm{~s}$. All the procedures were performed in duplicate and the beta-actin was used as a housekeeping gene, and the results were expressed using the formula $2^{-\Delta \Delta C T}$ [11]. The gene expression was categorized as upregulated or downregulated when normalized expression values were $>$ or $\leq 1$, respectively [12].

\section{Therapy}

All adult patients diagnosed with non-acute promyelocytic leukemia (APL)-acute myeloid leukemia (AML) were subjected to a $3+7$ protocol to induce complete remission (CR) [13]. APL patients were administered with doxorubicin for the first three days and then in combination with all-trans-retinoic acid (ATRA) until remission. Patients diagnosed with acute lymphoblastic 
leukemia (ALL) underwent the hyper-CVAD regimen, alternating high-dose MTX with ARA-C [14].

\section{Patient outcomes}

Patients were followed for up to four weeks (time required for double-induction therapy) for the evaluation of remission status. Complete remission (CR) is defined by $<5 \%$ blast cells in the bone marrow and $<1 \%$ in the peripheral blood with a total leukocytes count (TLC) $\geq 1500 / \mathrm{L}$ and platelet count $\geq 100,000 / \mathrm{L}$ with no evidence of extramedullary leukemia. Early death (ED) was defined as death within 30 days of the date of diagnosis [15]. Patients were followed up for six months to identify events including relapse (defined as the presence of blasts in the peripheral blood, $\geq 5 \%$ blasts in the bone marrow, or presence of extramedullary lesions in patients with a previously documented CR) or death. These parameters were recorded for the duration of the study to identify periods of disease-free survival (DFS) and overall survival (OS), respectively.

\section{Statistical analysis}

The data analysis was performed using SPSS 20.0. Nonparametric numerical data were presented as medians and ranges, parametric data were presented as means \pm standard deviations, and categorical data were presented as frequencies and percentages. Mann-Whitney $U$ test and Kruskal-wallis test with Dunn-Bonferroni post hoc method were used to compare medians in between two or multiple groups, respectively. Correlations were performed using Spearman coefficients. The analysis of non-numeric data was performed using Pearson's chi-square test or Fisher's exact test. The correlations between the parameters and treatment outcomes were evaluated by performing univariate and multivariate regressions analyses using the logistic regression test. Kaplan-Meier analysis with log-rank test and Cox regression analysis were performed to evaluate the impact on survival. $P$ values $\leq 0.05$ were considered to be statistically significant.

\section{Results}

\section{Patient characteristics}

Ninety-eight newly diagnosed adult acute leukemia patients were enrolled in this study, 70 patients diagnosed with AML, and 28 with ALL. 61 of the patients were male $(62.2 \%)$ and 37 were female (37.8\%). 15 healthy participants were also included in this study; 8 of them were male (53.3\%) and 7 female (46.7\%). Additional file 1: Supplementary Table 1 summarizes the demographics, clinical manifestations of the disease, and patient outcomes.

\section{Apoptotic indices and expression of anti-apoptotic genes} Highly significant differences were observed when comparing the apoptotic indices in both AML and ALL patients versus controls and ALL versus AML patients (all $P<0.001)$. However, no significant differences were observed regarding the expression of anti-apoptotic genes in comparison between acute leukemia patients and controls or between those diagnosed with AML versus ALL (Table 1 and Additional file 1: Supplementary Figure 1). Figure 1 shows the results of the flow cytometry of selected cases. Spearman correlation coefficients revealed that the expressions of the three antiapoptotic genes were highly correlated with one other. The correlations were as follows: MCL1 with $B C L 2$, $r=0.75 ; M C L 1$ with $B C L-X L, r=0.71$; and $B C L 2$ with $B C L-X L, r=0.62(P<0.001$ for each comparison).

\section{AML}

\section{Cytogenetic risk classification}

With respect to cytogenetics, 12 patients were classified as a favorable risk; 6 patients had $t(8: 21), 3$ had $t(15: 17)$ translocations, and 3 had inversion 16.37 patients with normal cytogenetics were classified as intermediate risk, whereas 21 were classified as poor risk. Likewise, 7

Table 1 Spontaneous apoptosis indices, MCL1, BCL2, BCL-XL gene expression in cases and controls

\begin{tabular}{|c|c|c|c|c|c|}
\hline & Control & AML & ALL & $P$ & Post hoc test* \\
\hline Annexine V & $1.1(0.1-1.5)$ & $4.2(0.3-13.6)$ & $14.3(2.2-18.6)$ & $<0.001$ & \multirow{6}{*}{$\begin{array}{l}\text { Control versus } A L L<\mathbf{0 . 0 0} \\
A M L \text { versus } A L L<\mathbf{0 . 0 0 1} \\
\text { Control versus } A M L<\mathbf{0 . 0 0 1}\end{array}$} \\
\hline Anexine\&PI ${ }^{\dagger}$ & $0.3(0.1-0.9)$ & $5.3(0.6-17.1)$ & $11.6(5.9-24.1)$ & $<0.001$ & \\
\hline Total apoptosis & $1.6(0.3-1.9)$ & $9.7(1.7-19.3)$ & $22.6(14.8-38.0)$ & $<0.001$ & \\
\hline MCL1 & $1.7(0.2-2.9)$ & $2.0(0.2-17.1)$ & $3.2(0.1-8.9)$ & NS & \\
\hline $\mathrm{BCL} 2$ & $0.8(0.2-4.4)$ & $2.4(0-29.7)$ & $3.9(0.2-16.6)$ & NS & \\
\hline$B C L-X L$ & $0.7(0.3-5.4)$ & $2.0(0-9.2)$ & $3.1(0.0-6.3)$ & NS & \\
\hline
\end{tabular}

Results are expressed as medians and ranges. Kruskal-wallis tests with Dunn-Bonferroni post hoc method were applied

${ }^{*}$ Results of the post hoc test were the same for all apoptosis indices

${ }^{\dagger}$ Propidium lodide

Significant $P$ values are written in bold; NS, not significant 

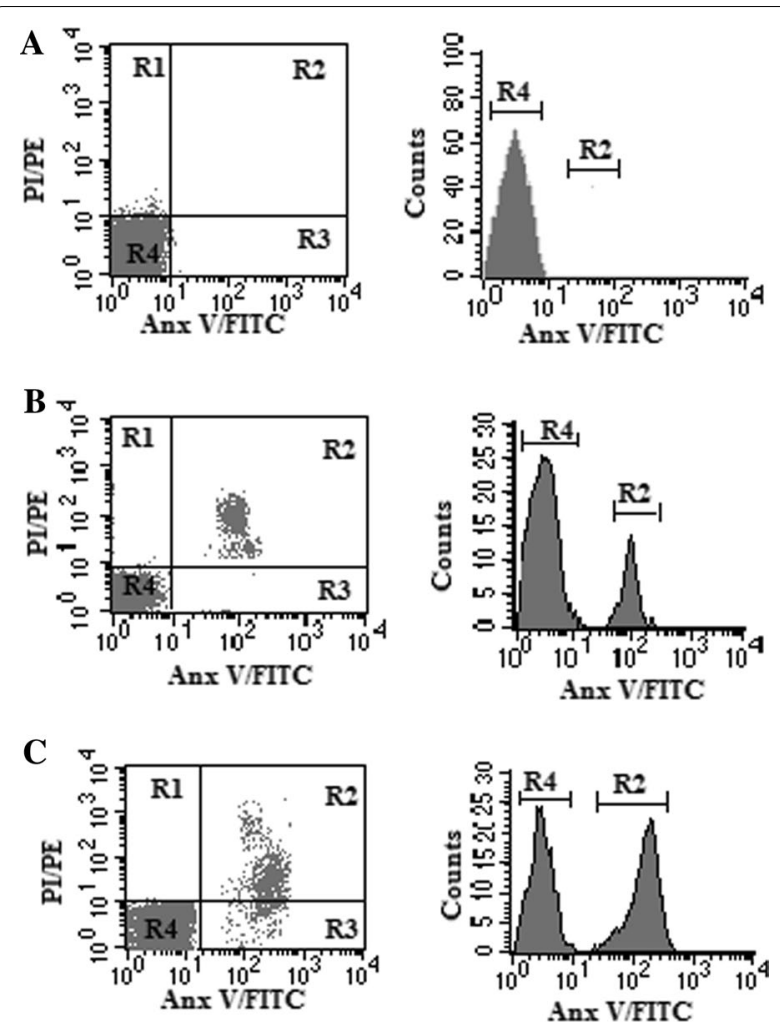

Fig. 1 Flow cytometry assessment of apoptotic cells. A Control, B acute myeloid leukemia, $\mathbf{C}$ acute lymphoblastic leukemia). Annexin V FITC (AnxV FITC) and propidium iodide PE (PI PE) fluorescence. Regions: $\mathbf{R} \mathbf{4}$ normal cells, $\mathbf{R} \mathbf{2}$ late apoptotic (AnxV +/PI+), $\mathbf{R} \mathbf{3}$ early apoptotic (AnxV+/PI-)

patients had trisomy 8,5 had trisomy 11,5 had $t(3: 3)$, and 4 had $t(9: 22)$.

\section{Spontaneous apoptotic indices}

Late and total apoptosis were both markedly decreased in patients who succumbed to ED $(P=0.006$ and $P=0.001$, respectively) (Table 2 ). Indices of spontaneous apoptosis did not correlate with any of the other prognostic parameters (data not presented) and showed no significant differences when comparing the results from the APL and non-APL-AML patients (Table 2).

\section{Expression of anti-apoptotic genes}

Among the 70 patients diagnosed with AML, the expression of $M C L 1, B C L 2$, and $B C L-X L$ was upregulated in 46 (65.7\%), 50 (71.4\%), and $46(65.7 \%)$ patients, respectively. The gene expression levels did not vary significantly in APL versus non-APL-AML patients. Furthermore, no significant correlations were observed between gene expression and other prognostic parameters. However, early, late, and total apoptosis were significantly increased in patients with upregulated expression of
BCL2 ( $P=0.03,0.003$, and 0.001 , respectively). The downregulated expression of BCL2 was more common in patients with $\operatorname{ED}(P=0.02$; Table 3$)$.

\section{Prognosis in AML patients}

Due to the fact that they are different disease entities, OS was evaluated independently in patients diagnosed with APL and those with non-APL-AML. The median values of total apoptosis in each group were used to dichotomize patients into those with high levels of cellular apoptosis and those with low levels [16]. In this study, Kaplan-Meier analysis was performed for all prognostic markers. Interestingly, none of them were significant markers in APL patients (data not shown). In non-APL-AML patients, spontaneous total apoptosis and performance status (PS) were significant predictors of the OS, whereas overexpression of BCL2 was associated with longer OS. Cox regression analysis revealed that spontaneous total apoptosis, BCL2 expression, and ECOG-PS are independent predictors of OS for patients diagnosed with non-APL-AML. Table 4 shows the hazard ratios and $P$ values. Figure 2 shows the Kaplan-Meier survival curves. None of the parameters evaluated in this study correlated with remission status or the likelihood of relapse (data not shown). Additional file 1: Supplementary Figure 2 presents the real-time PCR curves of BCL2 gene expression of selected cases.

\section{ALL}

\section{Cytogenetic risk classification}

Cytogenetic analysis revealed that 25 patients were classified as a favorable risk; 18 of these patients had a normal karyotype and 7 patients had $t(12 ; 21) .3$ patients were classified as a poor risk; 2 of these patients had $t$ (9; $22)$ and one had $t(4 ; 11)$.

\section{Spontaneous apoptotic indices}

Early apoptosis increased, whereas late apoptosis decreased in cases with T-cell ALL when compared with those diagnosed with B-cell ALL ( $P=0.001$ for each). Early and total apoptosis decreased in patients with poor PS as determined by the ECOG $(P=0.001)$ and also in patients who succumbed to $\operatorname{ED}(P=0.001$ and 0.002 , respectively; Table 2).

\section{Expression of anti-apoptotic genes}

Anti-apoptotic genes were upregulated in $60.7 \%$ of the patients. No correlations were observed between the expression levels of any of the three anti-apoptotic genes and other prognostic markers or outcomes (data not presented). 
Table 2 Early, late and total apoptosis in AML and ALL patients

\begin{tabular}{|c|c|c|c|c|c|c|}
\hline & Annxine V & $P$ & Annexine\&PI & $P$ & Total apoptosis & $P$ \\
\hline \multicolumn{7}{|l|}{ AML patients $(n=70)$} \\
\hline \multicolumn{7}{|l|}{$\mathrm{FAB}$} \\
\hline $\mathrm{APL}^{*}(n=11)$ & $4.2(0.3-6.2)$ & NS & $5.4(0.9-7.8)$ & NS & $6.3(3.1-13.3)$ & NS \\
\hline Non-APL $(n=59)$ & $4.3(0.3-13.6)$ & & $5.3(0.6-17.1)$ & & $9.8(1.7-19.3)$ & \\
\hline \multicolumn{7}{|l|}{ Performance status } \\
\hline $0 / 1(n=33)$ & $5.2(0.3-9.5)$ & NS & $5.5(0.6-14.6)$ & NS & $12.3(2.9-18.5)$ & NS \\
\hline $2 / 3(n=37)$ & $3.9(1.0-13.6)$ & & $4.1(0.6-17.2)$ & & $9.6(1.7-19.3)$ & \\
\hline \multicolumn{7}{|l|}{ Early death ${ }^{\dagger}$} \\
\hline Yes $(n=20)$ & $3.8(1.0-6.9)$ & NS & $3.4(0.7-7.6)$ & 0.006 & $8.8(1.7-12.5)$ & 0.001 \\
\hline No $(n=48)$ & $4.5(0.3-13.6)$ & & $5.6(0.6-17.1)$ & & $12.4(2.9-19.3)$ & \\
\hline \multicolumn{7}{|l|}{ ALL patients $(n=28)$} \\
\hline \multicolumn{7}{|l|}{$F A B$} \\
\hline B.ALL $(n=16)$ & $9.1(2.2-15.9)$ & 0.001 & $13.4(11.3-24.1)$ & 0.001 & $21.8(14.8-38.0)$ & NS \\
\hline T.ALL $(n=12)$ & $15.9(13.8-18.6)$ & & $7.7(5.9-9.1)$ & & $23.8(20.5-27.4)$ & \\
\hline \multicolumn{7}{|l|}{ Performance status } \\
\hline $0 / 1(n=18)$ & $15.4(13.5-18.6)$ & 0.001 & $8.3(5.9-24.1)$ & NS & $25.5(20.5-38.0)$ & 0.001 \\
\hline $2 / 3(n=10)$ & $6.3(2.2-9.3)$ & & $12.7(11.3-13.8)$ & & $19.2(14.8-22.4)$ & \\
\hline \multicolumn{7}{|l|}{ Early death } \\
\hline Yes $(n=5)$ & $3.7(3.1-8.5)$ & 0.001 & $12.7(11.3-13.1)$ & NS & $15.8(14.8-22.3)$ & 0.002 \\
\hline No $(n=23)$ & $14.6(2.2-18.6)$ & & $9.1(5.9-24.1)$ & & $24.0(14.9-38.0)$ & \\
\hline
\end{tabular}

*Acute Promyelocytic Leukemia

${ }^{\dagger}$ Two patients left hospital at the induction phase

Mann-Whitney's $U$ test was used

Significant $P$ values are written in bold; NS, not significant

Table 3 MCL1, BCL2, BCL-XL gene expression in AML cases $(n=70)$

\begin{tabular}{|c|c|c|c|c|c|c|c|c|c|}
\hline & \multicolumn{3}{|l|}{$M C L 1$} & \multicolumn{3}{|l|}{$B C L 2$} & \multicolumn{3}{|l|}{$B C L-X L$} \\
\hline & $\begin{array}{l}\text { Negative } \\
(n=24)\end{array}$ & Positive $(n=46)$ & $P$ & $\begin{array}{l}\text { Negative } \\
(n=20)\end{array}$ & Positive $(n=50)$ & $P$ & $\begin{array}{l}\text { Negative } \\
(n=24)\end{array}$ & Positive $(n=46)$ & $P$ \\
\hline \multicolumn{10}{|l|}{$F A B$} \\
\hline $\operatorname{APL}(n=11)^{*}$ & 5 & 6 & NS & 5 & 6 & NS & 5 & 6 & NS \\
\hline $\begin{array}{l}\text { Non-APL } \\
(n=59)\end{array}$ & 19 & 40 & & 15 & 44 & & 19 & 40 & \\
\hline \multicolumn{10}{|l|}{ Performance status } \\
\hline $0 / 1(n=33)$ & 14 & 19 & NS & 8 & 25 & NS & 16 & 17 & NS \\
\hline $2 / 3(n=37)$ & 10 & 27 & & 12 & 25 & & 8 & 29 & \\
\hline \multicolumn{10}{|l|}{ Early death $^{\dagger}$} \\
\hline No $(n=48)$ & 17 & 31 & NS & 10 & 38 & 0.02 & 17 & 31 & NS \\
\hline Yes $(n=20)$ & 7 & 13 & & 10 & 10 & & 7 & 13 & \\
\hline \multicolumn{10}{|c|}{ Apoptosis medians (ranges) } \\
\hline Annxine V & $3.8(0.4-9.1)$ & $4.9(0.3-13.6)$ & NS & $2.7(0.4-8.4)$ & $4.8(0.3-13.6)$ & 0.03 & $3.8(0.4-9.5)$ & $4.5(0.3-13.6)$ & NS \\
\hline$A n \times\left. \& P\right|^{\ddagger}$ & $3.4(0.6-13.9)$ & $5.5(0.6-17.1)$ & NS & $2.5(0.6-7.8)$ & $5.5(0.6-17.1)$ & 0.003 & $3.5(0.6-12.3)$ & $5.5(0.6-17.1)$ & NS \\
\hline Total apoptosis & $8.3(1.7-18.6)$ & $10.4(2.9-19.3)$ & NS & $4.6(1.7-14.3)$ & $11.1(2.9-19.3)$ & 0.001 & $8.3(1.7-17.7)$ & $10.4(2.9-19.3)$ & NS \\
\hline
\end{tabular}

*Acute Promyelocytic Leukemia

${ }^{\dagger}$ Two patient left hospital at the inductionphase

${ }^{\ddagger}$ Annexine $V$ and Propidium lodide

Mann-Whitney's $U$ test, Pearson Chi-square or Fisher exact test was carried out as specified in the method section

Significant $P$ values are written in bold; NS, not significant 
Table 4 Univariate and multivariate analyses of prognostic factors for overall survival in non-APL patients

\begin{tabular}{|c|c|c|c|c|}
\hline \multirow[t]{2}{*}{ Prognostic factors } & \multicolumn{2}{|l|}{ Univariate analysis } & \multicolumn{2}{|l|}{ Multivariate analysis } \\
\hline & Hazard Ratio $(95 \% \mathrm{CI})$ & $P$ & Hazard Ratio $(95 \% \mathrm{Cl})$ & $P$ \\
\hline Performance status & $186(2.5-140)$ & 0.004 & $15.6(2.1-118)$ & 0.008 \\
\hline Total apoptosis & $5.8(1.9-17.9)$ & 0.002 & $4.7(1.5-14.4)$ & 0.007 \\
\hline$B C L 2$ & $0.2(0.08-0.6)$ & 0.001 & $0.3(0.1-0.7)$ & 0.01 \\
\hline Age & $2.1(0.7-6.6)$ & 0.2 & & \\
\hline Gender & $0.5(0.2-1.5)$ & 0.2 & & \\
\hline Cytogenetics & $0.6(0.3-1.4)$ & 0.3 & & \\
\hline $\mathrm{TLC}^{*}$ & $1.7(0.5-5.1)$ & 0.3 & & \\
\hline MCL1 & $0.9(0.3-2.8)$ & 0.9 & & \\
\hline$B C L-X L$ & $0.9(0.3-2.8)$ & 0.9 & & \\
\hline
\end{tabular}

*Total leukocytes count

Significant $P$ values are written in bold
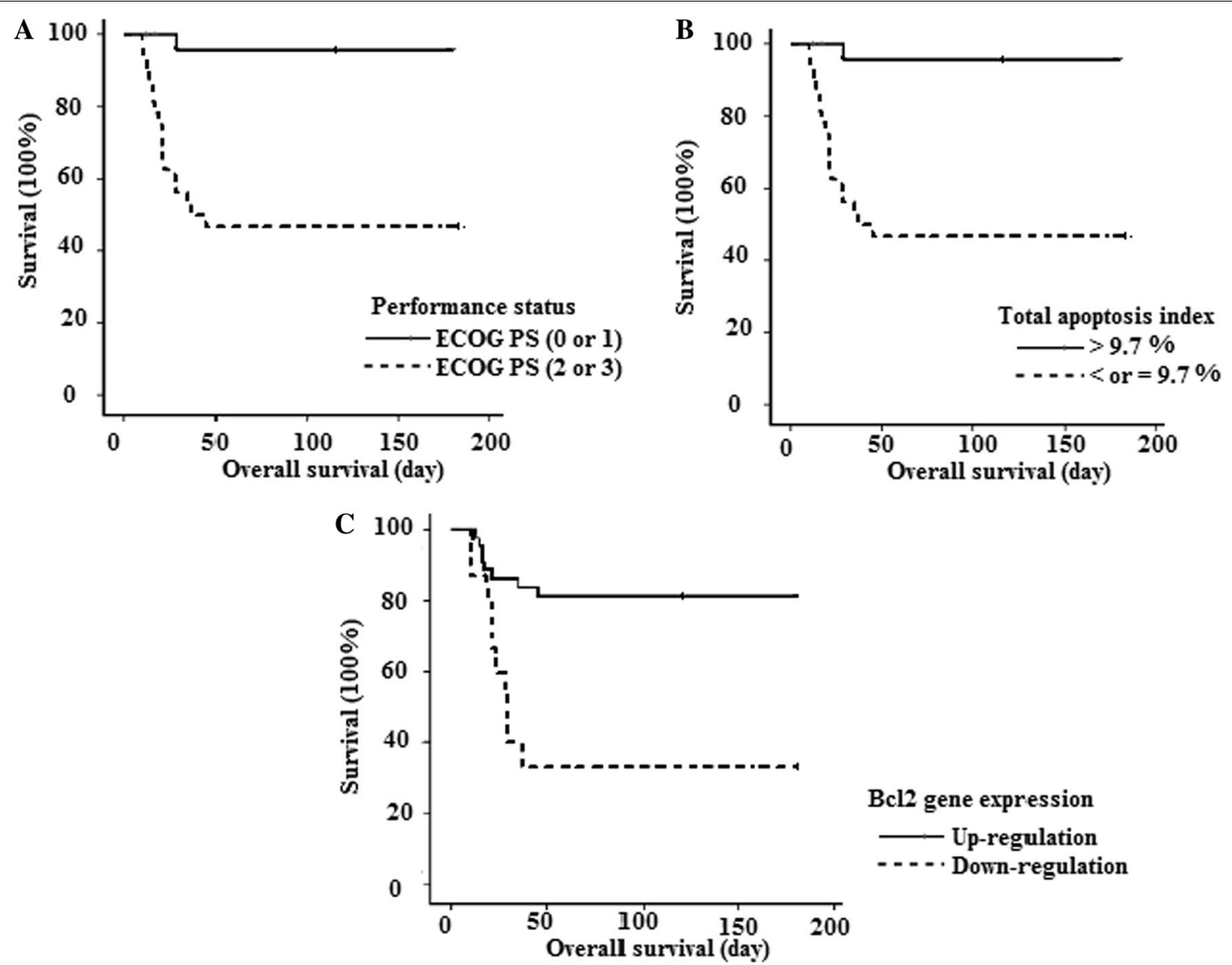

Fig. 2 Kaplan-Meier survival curves and log-rank test. A Performance status. B Total apoptosis. C BCL2 gene expression, in non-acute promyelocytic leukemia_AML patients. Eastern Cooperative Oncology Performance Status (ECOG-PS)

\section{Prognosis in ALL patients}

Kaplan-Meier analysis of all variants revealed that PS was the only useful indicator of the OS (hazard ratio $=6.6$,
95\% CI (1.1-38.0), $P=0.03$, data not shown). Most ALL patients responded to therapy and did not undergo relapse after remission; patients with non-remission 
or who relapsed after CR were too few in number to be analyzed.

\section{Discussion}

The imbalance between apoptosis and cell proliferation is the hallmark feature of acute leukemia. To our knowledge, this is the first prospective study that focuses on the expression of $M C L 1, B C L 2$, and $B C L-X L$ and spontaneous apoptosis in adult leukemia patients in Egypt. Only few previous studies have considered these three anti-apoptosis genes in adult AML. Furthermore, no previously published literature that features similar parameters in a study of adult ALL was included in the present study.

In this study, ED was observed in $28.5 \%$ of the patients diagnosed with AML and $17.8 \%$ of those with ALL. Previous studies that focused on this point had various conclusions. For example, El-Zawahry et al. [17] reported a 39\% death rate in adult AML patients, whereas Zawarm et al. [18] reported $12.5 \%$. Similarly, Thomas et al. [19] identified ED in $24.6 \%$ of adult patients with ALL, whereas da Silva et al. [20] identified ED in $16.9 \%$.

The ECOG-PS is a well-known predictor for the OS among patients with both AML and ALL, which was confirmed in the present study. Malkan et al. [21] reported that the ECOG-PS score at diagnosis was the main independent factor influencing ED; this group indicated the need to identify parameters associated with performance status that may have a direct influence on ED.

\section{Spontaneous apoptotic indices}

Early, late, and total apoptosis were significantly increased in acute leukemia patients compared to healthy controls. These findings are in accordance with the results of Lin et al. [22] who demonstrated that spontaneous apoptosis is increased in AML and ALL bone marrow cells compared to healthy control bone marrow cells, and Banker et al. [23] who observed that normal bone marrow myeloid cells have consistent low levels of spontaneous apoptosis than de novo AML cells.

The up-regulation of anti-apoptotic machinery in acute leukemia is associated with a compensatory enhancement in the pro-apoptotics, such as B-cell lymphoma protein 2 (Bcl-2)-associated $\mathrm{X}(\mathrm{BAX})$ gene transcripts and protein elevation in AML [12, 24], Fas (Apo-1/CD95) in AML and ALL [25], Caspases 2 and 3 in AML and ALL patients, respectively [26, 27]. This can explain the increased overall apoptosis in leukemia cells when compared to the normal bone marrow or peripheral blood cells. On the other hand, levels of spontaneous apoptosis in leukemic CD34+cells were lower in ALL and significantly lower in AML than normal bone marrow progenitor $(\mathrm{CD} 34+)$ cells [22], reflecting the survival advantages gained by leukemia cells over their normal counterparts.

Furthermore, cells from ALL patients were more prone to apoptosis than those from AML patients. These findings are consistent with the results of Savitskiy et al. [28] who evaluated the spontaneous apoptosis in cultured leukemic cells. Porwit-MacDonald et al. [29] observed that the expression of $B C L 2$ protein in myeloblast is higher than that in lymphoblast, and this can explain accelerated apoptosis in ALL more than AML. In a comparison between the two lineages, Smith et al. [30] found that AML cell lines displayed the least apoptosis and the more resistance to anti-leukemia drugs, while ALL cell lines were higher in apoptosis and more sensitive to the therapeutic agents, and they concluded that the amount of spontaneous apoptosis in acute leukemia cells paralleled their drug sensitivity either in vitro or in vivo.

\section{In AML patients}

In this study, we identified total apoptosis as a useful independent predictor for OS for patients diagnosed with non-APL-AML. At this time, very few studies have focused on apoptosis as a prognostic marker in patients with AML. Smith et al. [30] and Pluta et al. [31] reported the role of apoptosis in predicting treatment outcomes. By contrast, Deren-Wagemann et al. [32] found that spontaneous apoptosis had no prognostic value in AML patients.

\section{In ALL patients}

Similar to the findings of the present study, Savitskiy et al. [28] reported lower rates of early apoptosis and higher rates of late apoptosis in patients diagnosed with B-cell ALL compared to those with T-cell ALL, although total apoptosis was not significantly different. Although spontaneous apoptosis was significantly lower in patients who underwent ED, this parameter was not a significant predictor of OS. Singh et al. [16] found that apoptosis was not a useful prognostic marker in children diagnosed with ALL. However, Kapoor and Singh [33] noted that ongoing studies have revealed promising results with respect to the future utilization of apoptotic markers for predicting clinical outcomes.

\section{Expression of anti-apoptotic genes}

Although medians and ranges documenting the expression of $M C L 1, B C L 2$, and $B C L-X L$ were overall higher in patients with acute leukemia compared to controls, these differences failed to reach any statistical significance. This may be attributed to the relatively small sample size represented by our cohort. Li et al. [1] and Zhou et al. [34] found that the gene expressions of $M C L 1$ and $B C L 2$ were 
upregulated in AML patients, respectively. In another study, Schaich et al. [35] found that $B C L 2$ and $B C L$ $X L$ were upregulated in $13 \%$ and $39 \%$ of AML patients, respectively. Hogarth and Hall [36] reported the overexpression of $M C L 1$ and $B C L 2$ proteins in all samples from 47 children with ALL, although $B C L-X L$ was overexpressed in only 6 of these patients.

\section{In AML patients}

In this study, expression levels of $M C L 1$ and $B C L-X L$ failed to predict poor outcomes associated with AML. In contrast, Li et al. [1] reported that $M C L 1$ is a strong independent predictor of remission and OS in non-APLAML patients. Interestingly, this was the only previous study that has considered the expression of MCL1 as having prognostic value in adult AML. However, future studies will be needed to confirm or refute our findings. Our results agree with those of Schaich et al. [35] who reported that $B C L-X L$ gene expression had no significant impact on OS and DFS. Furthermore, our results do not support their findings on $B C L-X L$ gene expression being a significant negative indicator of response to therapy.

In this study, univariate and multivariate analyses revealed that $B C L 2$ was an independent predictor for OS in non-APL-AML patients. Although it is a major suppressor of apoptosis and expected to be associated with poor outcome, the expression of $B C L 2$ resulted in paradoxically higher levels of both late and total apoptosis and longer OS than was observed among patients with $B C L 2$ down-regulation. Kulsoom et al. [12] noted that the role of $B C L 2$ in predicting outcomes is a controversial subject. As for example, in AML patients, Campos et al. [37], Maung et al. [38], Lauria et al. [39] reported that high $B C L 2$ levels was associated with poor response to therapy, Aref et al. [40] reported that increased $B C L 2$ expression was associated with relapse, while according to Karakas et al. [41], the OS and DFS were significantly worse in patients with high levels of bcl-2 mRNA. Kornblau et al. [42] reported that high $B C L 2$ expression was associated with a shorter OS in the favorable and intermediate cytogenetic groups, while with a longer OS and DFS in the poor cytogenetic group. Kulsoom et al. [12] found that BCL2 levels were higher among responders although it failed to reach statistical significance. Sahu and Kumar Jena [43] observed that BCL2-positive patients had better OS as compared to BCL2-negative patients and that low level of $\mathrm{Bcl}-2$ was associated with lower CR rates, shorter DFS and OS. In contrast, other studies showed no significant correlation with CR rate, DFS, or OS [34, 44].

Kulsoom et al. [12] attributed these contrasts to the differences in sample size, methods of detection, and pathology of patients. Kornblau et al. [42] considered the possibility that factors other than the characterized anti-apoptotic proteins may have an influence on overall apoptosis, including chromosomal aberrations and/ or the counteracting properties of pro-apoptotic proteins [34].

Increased $B C L 2$ expression may disturb the balance of other BCL2 family members including the expression of pro-apoptotic proteins, such as B-cell lymphoma protein 2 (Bcl-2)-associated X (Bax), BCL2 Antagonist/Killer1 (Bak1), and BCL2 Associated Agonist of Cell Death (Bad) [45]. Bax has been suspected to be a good prognostic marker for being a pro-apoptotic protein, but similar to $B C L 2$, results are controversy, so it is more reliable to study $B C L 2$ and Bax as a ratio rather than studying them individually [46].

The prognostic impact of $B C L 2$ expression in AML varies with cytogenetics [42], a post-transcription regulation of $B C L 2$ activity may occur depending on these genetic factors; for instance, the tumor suppressor protein (p53) that can regulate $\mathrm{Bcl}-2$ levels and activity through diverse mechanisms or induce transactivation of pro-apoptotic $B C L 2$ family members [47], so the presence of wild or mutated types of p53 can impact the overall patients' outcome $[48,49]$. The role of $B C L 2$ and its homologues in cell cycle regulation and reduction of proliferation can be another explanation for this finding [50].

Post-transcriptional regulation is an important effector on $B C L 2$ protein levels and activity. For example, miR$15 a$ and $m i R-16-1$ that can inhibit $\mathrm{Bcl} 2$ expression, or the RNA-BP nucleolin that has been shown to increase $\mathrm{Bcl} 2$ expression by enhancing mRNA stability. [51]. Therefore, the gene expression level may not completely reflect the final protein level and the overall activity. So, studying the protein levels besides the gene expression levels can be more convenient.

\section{In ALL patients}

Expression of any of the three aforementioned genes had no significant role with respect to the prognosis of ALL; this finding is consistent with the results of Hogarth and Hall [36] who reported that none of these three proteins had any significant influence on the prognosis and eventfree survival associated with ALL in children. In contrast, Abdelsalam et al. [52] reported that the overexpression of $B C L 2$ and $B C L-X L$ had a significant influence on the prognosis and event-free survival associated with ALL in children.

\section{Conclusion}

Spontaneous total apoptosis and $B C L 2$ gene expression may be valuable independent markers for OS in patients with non-APL-AML. Furthermore, in ALL patients decreased levels of spontaneous apoptosis were 
associated with ED, although this was not a significant predictor of OS.

\section{Limitations}

This is a single-center study. The sample size was relatively small and the duration of follow-up was relatively short.

\section{Recommendations}

Multi-center studies including larger cohorts to consider the prognostic value of anti-apoptotic and pro-apoptotic gene expression as well as spontaneous or induced total leukocyte apoptosis are recommended. The expansion of the current study in the same center is also encouraged to support our findings. Further studies concerning the level of anti-apoptotic protein expression in correlation with prognosis is recommended.

\section{Abbreviations}

CR: Complete remission; ECOG: Eastern Cooperative Oncology Group; ED: Early death; LCs: Leukemia cells; OS: Overall survival; PS: Performance status; PB: Peripheral blood; PI: Propidium iodide; AML: Acute myeloid leukemia; ALL: Acute lymphoblastic leukemia; APL: Acute promyelocytic leukemia; FITC: Fluorescein isothiocyanate; DFS: Disease-free survival; OS: Overall survival.

\section{Supplementary Information}

The online version contains supplementary material available at https://doi. org/10.1186/s43042-021-00210-8.

Additional file 1. Supplementary Table 1. Demographic features, clinical presentations, and laboratory investigations of patients. Supplementary Figure 1. boxplots of early (Annexin V), late (Annexin V/propidium iodide), and total apoptosis. MCL1, BCL2 and BCL-XL gene expression in acute lymphoblastic leukemia and acute myeloid leukemia patients and controls. Supplementary Figure 2. Real-time PCR amplification curves of two AML (M2) patients. (A) A patient who survived for 29 days with a $B C L 2$ gene expression of 0.26 . (B) A patient who survived till the end of the study "180 days" with a BCL2 gene expression of 10.06. The line with circular dots represents the $B C L 2$ gene curve, whereas the line with rectangular dots represents the beta-actin gene curve. AML, acute myeloid leukemia.

Acknowledgements

No acknowledgments to declare.

\section{Authors' contributions}

The requirements for authorship have been met. All authors contributed to the study conceptualization and design. The original idea was the first and last author's, they also contributed to sample processing, results collection, data analysis, manuscript writing, the third author contributed to patient's selection, history taking, and data collection. The second and fourth authors contributed to manuscript writing and revision. Authors certify that we have personally written at least 90 percent of the manuscript. Finally, the manuscript has been read and approved by all the authors. All authors are responsible for reported research. All authors read and approved the final manuscript.

\section{Funding}

This research did not receive any specific grant from funding agencies in the public, commercial, or not-for-profit sectors.
Availability of data and materials

Data and materials are available on request from authors.

\section{Declarations}

\section{Ethics approval and consent to participate}

The Institutional Review Board (IRB) and the ethical committee of Zagazig University Hospitals approved this study. All subjects provided written, informed consent prior to enrollment (approval number IRB\# 5897-October $01,2019)$. The study was performed in accordance with the declarations of Helsinki of 1964, revised 2013 available at https://www.wma.net/policies-post/ wma-declaration-of-helsinki-ethical-principles-for-medical-research-involvinghuman-subjects.

\section{Consent for publication}

Not applicable.

\section{Competing interests}

Authors have no competing interest to declare.

\section{Author details}

${ }^{1}$ Clinical Pathology Department, Faculty of Medicine, Zagazig University, Zagazig City, Al Sharqia Governorate, Egypt. ${ }^{2}$ Medical Microbiology and Immunology Department, Faculty of Medicine, Zagazig University, Zagazig City, Al Sharqia Governorate, Egypt. ${ }^{3}$ Internal Medicine Department, Faculty of Medicine, Zagazig University, Zagazig City, Al Sharqia Governorate, Egypt. ${ }^{4}$ Medical Biochemistry Department, Faculty of Medicine, Zagazig University, Zagazig City 44519, Al Sharqia Governorate, Egypt.

Received: 2 June 2021 Accepted: 10 September 2021

Published online: 05 November 2021

\section{References}

1. Li X-X, Zhou J-D, Wen X-M, Zhang T-J, Wu D-H, Deng Z-Q et al (2019) Increased MCL-1 expression predicts poor prognosis and disease recurrence in acute myeloid leukemia. OncoTargets Ther 12:3295-3304. https://doi.org/10.2147/OTT.S194549

2. Rieger AM, Nelson KL, Konowalchuk JD, Barreda DR (2011) Modified annexin $\mathrm{V} /$ propidium iodide apoptosis assay for accurate assessment of cell death. J Vis Exp 50:2597. https://doi.org/10.3791/2597

3. Nanni J, Simonetti G, Marconi G, Fontana MC, Bruno S, Papayannidis C et al (2017) A three-genes signature of anti-apoptotic genes showed different mechanisms in preventing apoptosis in acute myeloid Leukemia cells and could provide an useful model to establish the proper $\mathrm{BH} 3-$ mimetich drug or combination. Blood 130(Suppl 1):4969

4. Swerdlow SH (2008) WHO classification of tumours of haematopoietic and lymphoid tissues. WHO Classif Tumours 22008:439

5. Fateen MA, El Demerdash DM, Zayed RA, Mattar MM (2019) Role of physical function in predicting short-term treatment outcome in Egyptian acute myeloid leukemia patients: a single center experience. Hematol Transfus Cell Ther 41:17-24

6. Lakshmanan I, Batra SK (2013) Protocol for apoptosis assay by flow cytometry using annexin V staining method. Bio Protoc 3(6):e374. https:// doi.org/10.21769/bioprotoc.374

7. Tyagi A, Pramanik R, Bakhshi R, Vishnubhatla S, Bakhshi S (2019) Apoptosis: a biomarker of high-risk phenotype in pediatric acute myeloid leukemia? Int J Lab Hematol 41(1):141-147. https://doi.org/10.1111/ijlh. 12939

8. Merchant SH, Gonchoroff NJ, Hutchison RE (2001) Apoptotic index by annexin $\mathrm{V}$ flow cytometry: adjunct to morphologic and cytogenetic diagnosis of myelodysplastic syndromes. Cytometry 46(1):28-32. https:// doi.org/10.1002/1097-0320(20010215)46:1\%3c28::aid-cyto1034\%3e3.0. co;2-h

9. Papageorgiou SG, Kontos CK, Pappa V, Thomadaki H, Kontsioti F, Dervenoulas J et al (2011) The novel member of the BCL2 gene family, BCL2L12, is substantially elevated in chronic lymphocytic leukemia patients, supporting its value as a significant biomarker. Oncologist 16(9):1280-1291. https://doi.org/10.1634/theoncologist.2010-0349 
10. Gasparotto EPL, Tognon R, Ferreira AF, Oliveira GLV, Palma PVB, Zanichelli MA et al (2011) Deregulated expression of A1, BCl-2, BCl-xL, and MCl-1 antiapoptotic proteins and Bid, Bad, and Bax proapoptotic genes in polycythemia vera patients. Braz J Pharm Sci 47(4):873-886

11. Livak KJ, Schmittgen TD (2001) Analysis of relative gene expression data using real-time quantitative PCR and the $2^{-\triangle \triangle C T}$ method. Methods 25(4):402-408. https://doi.org/10.1006/meth.2001.1262

12. Kulsoom B, Shamsi TS, Afsar NA, Memon Z, Ahmed N, Hasnain SN (2018) Bax, BCl-2, and Bax/BCl-2 as prognostic markers in acute myeloid leukemia: are we ready for $\mathrm{BCl}$-2-directed therapy? Cancer Manag Res 10:403-416. https://doi.org/10.2147/CMAR.S154608

13. Tefferi A, Letendre $L$ (2012) Going beyond $7+3$ regimens in the treatment of adult acute myeloid leukemia. J Clin Oncol 30(20):2425-2428. https://doi.org/10.1200/jco.2011.38.9601

14. Kantarjian HM, O'Brien S, Smith TL, Cortes J, Giles FJ, Beran M et al (2000) Results of treatment with hyper-CVAD, a dose-intensive regimen, in adult acute lymphocytic leukemia. J Clin Oncol 18(3):547-561. https://doi.org/10.1200/jco.2000.18.3.547

15. Xu F, Wang C, Yin C, Jiang X, Jiang L, Wang Z et al (2017) Analysis of early death in newly diagnosed acute promyelocytic leukemia patients. Medicine (Baltimore) 96(51):e9324. https://doi.org/10.1097/ MD.0000000000009324

16. Singh A, Bhatia P, Trehan A, Bansal D, Singh A, Bhatia A (2018) Low spontaneous apoptosis index at diagnosis predicts a high-risk phenotype in paediatric acute lymphoblastic leukaemia. Indian J Med Res 147(3):248-255. https://doi.org/10.4103/ijmr.IJMR_303_16

17. El-Zawahry H, Zeeneldin A, Samra M, Mattar M, El Gammal M, El-Samee A et al (2007) Cost and outcome of treatment of adults with acute myeloid leukemia at the National Cancer Institute-Egypt. J Egypt Natl Cancer Inst 19:106-113

18. Zawam H, Salama R, Alsirafy S, Bishr M (2018) Treatment outcome of acute myeloid leukemia in Egypt: a developing country perspective. Int J Cancer Tremnt 1:53-59

19. Thomas X, Olteanu N, Charrin C, Lhéritier V, Magaud JP, Fiere D (2001) Acute lymphoblastic leukemia in the elderly: the Edouard Herriot Hospital experience. Am J Hematol 67(2):73-83

20. da Silva Junior WF, Medina AB, Yamakawa PE, Buccheri V, Velloso ED, Rocha V (2018) Treating adult acute lymphoblastic leukemia in Brazil-increased early mortality using a german multicenter acute lymphoblastic leukemia-based regimen. Clin Lymphoma Myeloma Leuk 18(6):e255-e259

21. Malkan UY, Gunes G, Eliacik E, Haznedaroglu IC, Etgul S, Aslan T et al (2015) The factors affecting early death after the initial therapy of acute myeloid leukemia. Int J Clin Exp Med 8(12):22564

22. Lin CW, Manshouri T, Jilani I, Neuberg D, Patel K, Kantarjian $\mathrm{H}$ et al (2002) Proliferation and apoptosis in acute and chronic leukemias and myelodysplastic syndrome. Leuk Res 26(6):551-559. https://doi.org/10. 1016/S0145-2126(01)00170-9

23. Banker DE, Groudine M, Norwood T, Appelbaum FR (1997) Measurement of spontaneous and therapeutic agent-induced apoptosis with BCL-2 protein expression in acute myeloid leukemia. Blood 89(1):243255. https://doi.org/10.1182/blood.V89.1.243

24. Sharawat SK, Raina V, Kumar L, Sharma A, Bakhshi R, Vishnubhatla S et al (2014) Quantitative assessment of BAX transcript and flow cytometric expression in acute myeloid leukemia: a prospective study. Hematology (Amsterdam, Netherlands) 19(7):404-411. https://doi.org/ 10.1179/1607845413y.0000000146

25. Nosair N, Bar ESAE, Taha A, Gawaly A (2014) Fas (CD95) expression as a prognostic marker in acute leukemia and blastic transformation phase in chronic myeloid leukemia. Egypt J Haematol 39(1):25-31. https:// doi.org/10.4103/1110-1067.124843

26. Estrov Z, Thall PF, Talpaz M, Estey EH, Kantarjian HM, Andreeff M et al (1998) Caspase 2 and caspase 3 protein levels as predictors of survival in acute myelogenous leukemia. Blood 92(9):3090-3097

27. Faderl S, Thall PF, Kantarjian HM, Talpaz M, Harris D, Van Q et al (1999) Caspase 2 and caspase 3 as predictors of complete remission and survival in adults with acute lymphoblastic leukemia. Clin Cancer Res 5(12):4041-4047

28. Savitskiy VP, Shman TV, Potapnev MP (2003) Comparative measurement of spontaneous apoptosis in pediatric acute leukemia by different techniques. Cytometry B Clin Cytom 56(1):16-22. https://doi.org/10. 1002/cyto.b.10056

29. Porwit-MacDonald A, Ivory K, Wilkinson S, Wheatley K, Wong L, Janossy $\mathrm{G}$ (1995) BCl-2 protein expression in normal human bone marrow precursors and in acute myelogenous leukemia. Leukemia 9(7):1191-1198

30. Smith BD, Bambach BJ, Vala MS, Barber JP, Enger C, Brodsky RA et al (1998) Inhibited apoptosis and drug resistance in acute myeloid leukaemia. Br J Haematol 102(4):1042-1049. https://doi.org/10.1046/j. 1365-2141.1998.00854.x

31. Pluta A, Wrzesien-Kus A, Cebula-Obrzut B, Wolska A, SzmigielskaKaplon A, Czemerska M et al (2010) Influence of high expression of Smac/DIABLO protein on the clinical outcome in acute myeloid leukemia patients. Leuk Res 34(10):1308-1313. https://doi.org/10.1016/j. leukres.2009.11.030

32. Deren-Wagemann IE, Kuliczkowski K (2019) Significance of apoptosis and autophagy of leukemic blasts for the outcomes of acute myeloid leukemia patients. Adv Clin Exp Med. 28(7):861-869. https://doi.org/10. 17219/acem/93849

33. Kapoor G, Singh N (2018) Role of apoptotic markers in paediatric acute lymphoblastic leukaemia. Indian J Med Res 147(3):225-227. https://doi. org/10.4103/ijmr.IJMR_906_17

34. Zhou J-D, Zhang T-J, Xu Z-J, Gu Y, Ma J-C, Li X-X et al (2019) BCL2 overexpression: clinical implication and biological insights in acute myeloid leukemia. Diagn Pathol 14(1):68. https://doi.org/10.1186/ s13000-019-0841-1

35. Schaich M, IIImer T, Seitz G, Mohr B, Schakel U, Beck JF et al (2001) The prognostic value of $\mathrm{BCl}-\mathrm{XL}$ gene expression for remission induction is influenced by cytogenetics in adult acute myeloid leukemia. Haematologica 86(5):470-477

36. Hogarth LA, Hall AG (1999) Increased BAX expression is associated with an increased risk of relapse in childhood acute lymphocytic leukemia. Blood 93(8):2671-2678. https://doi.org/10.1182/blood.V93.8.2671

37. Campos L, Rouault JP, Sabido O, Oriol P, Roubi N, Vasselon C et al (1993) High expression of bcl-2 protein in acute myeloid leukemia cells is associated with poor response to chemotherapy. Blood 81(11):3091-3096

38. Maung ZT, MacLean FR, Reid MM, Pearson AD, Proctor SJ, Hamilton PJ et al (1994) The relationship between bcl-2 expression and response to chemotherapy in acute leukaemia. Br J Haematol 88(1):105-109. https://doi.org/10.1111/j.1365-2141.1994.tb04984.x

39. Lauria F, Raspadori D, Rondelli D, Ventura MA, Fiacchini M, Visani G et al (1997) High bcl-2 expression in acute myeloid leukemia cells correlates with CD34 positivity and complete remission rate. Leukemia 11(12):2075-2078. https://doi.org/10.1038/sj.leu.2400854

40. Aref S, Salama O, Al-Tonbary Y, Mansour A (2004) Assessment of bcl-2 expression as modulator of fas mediated apoptosis in acute leukemia. Hematology (Amsterdam, Netherlands) 9(2):113-121

41. Karakas T, Maurer U, Weidmann E, Miething CC, Hoelzer D, Bergmann $\mathrm{L}$ (1998) High expression of bcl-2 mRNA as a determinant of poor prognosis in acute myeloid leukemia. Ann Oncol 9(2):159-165. https:// doi.org/10.1023/a:1008255511404

42. Kornblau SM, Thall PF, Estrov Z, Walterscheid M, Patel S, Theriault A et al (1999) The prognostic impact of BCL2 protein expression in acute myelogenous leukemia varies with cytogenetics. Clin Cancer Res 5(7):1758-1766

43. Sahu G, Kumar Jena R (2011) Clinical significance of P53 and BCl-2 in acute myeloid leukemia patients of Eastern India. Hematol Rep. https:// doi.org/10.4081/hr.2011.e28

44. Kaparou M, Choumerianou D, Perdikogianni C, Martimianaki G, Kalmanti M, Stiakaki E (2013) Enhanced levels of the apoptotic BAX/ $\mathrm{BCL}-2$ ratio in children with acute lymphoblastic leukemia and highrisk features. Genet Mol Biol 36:7-11

45. Cory S, Huang DC, Adams JM (2003) The BCl-2 family: roles in cell survival and oncogenesis. Oncogene 22(53):8590-8607. https://doi.org/ 10.1038/sj.onc.1207102

46. Del-Poeta G, Venditti A, Del-Principe MI, Maurillo L, Buccisano F, Tamburini A et al (2003) Amount of spontaneous apoptosis detected by $\mathrm{Bax} / \mathrm{BCl}-2$ ratio predicts outcome in acute myeloid leukemia (AML) Presented in part at the 42nd annual meeting of the American Society of Hematology, San Francisco, CA, December 1-5, 2000.46. Blood 101(6):2125-2131 
47. Hemann MT, Lowe SW (2006) The p53-Bcl-2 connection. Cell Death Differ 13(8):1256-1259. https://doi.org/10.1038/sj.cdd.4401962

48. Hemann MT, Lowe SW (2006) The p53-Bcl-2 connection. Cell Death Differ 13(8):1256-1259. https://doi.org/10.1038/sj.cdd.4401962

49. Sahu G, Jena RK (2011) Clinical significance of P53 and Bcl-2 in acute myeloid leukemia patients of Eastern India. Hematol Rep 3(3):e28. https://doi.org/10.4081/hr.2011.e28

50. O'Reilly LA, Huang DC, Strasser A (1996) The cell death inhibitor BCl-2 and its homologues influence control of cell cycle entry. EMBO J 15(24):6979-6990

51. Willimott S, Wagner SD (2010) Post-transcriptional and post-translational regulation of Bcl2. Biochem Soc Trans 38(6):1571-1575. https:// doi.org/10.1042/bst0381571
52. Abdelsalam L, Elshobaky M, El-Araby R, Gad A, Khalifa M, Amer E et al (2017) Expression of beclin-1 and apoptosis-related genes in childhood acute lymphoblastic leukemia. Arch Med Sci Civiliz Dis 2:168-173. https://doi.org/10.5114/amscd.2017.72535

\section{Publisher's Note}

Springer Nature remains neutral with regard to jurisdictional claims in published maps and institutional affiliations.

\section{Submit your manuscript to a SpringerOpen ${ }^{\circ}$ journal and benefit from:}

- Convenient online submission

- Rigorous peer review

- Open access: articles freely available online

- High visibility within the field

- Retaining the copyright to your article

Submit your next manuscript at $\boldsymbol{\nabla}$ springeropen.com 